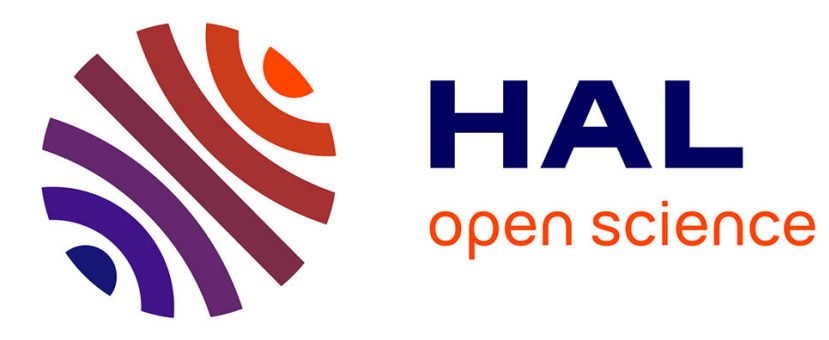

\title{
Robotic-flapper maneuvers and fruitfly turns
}

Franck Ruffier

\section{To cite this version:}

Franck Ruffier. Robotic-flapper maneuvers and fruitfly turns: Studies of an aerial robot help explain rapid banked turns in the fruitfly. Science, 2018, 361 (6407), pp.1073 - 1074. 10.1126/science.aau7350 . hal-01876298

\section{HAL Id: hal-01876298 \\ https://hal-amu.archives-ouvertes.fr/hal-01876298}

Submitted on 10 Jan 2019

HAL is a multi-disciplinary open access archive for the deposit and dissemination of scientific research documents, whether they are published or not. The documents may come from teaching and research institutions in France or abroad, or from public or private research centers.
L'archive ouverte pluridisciplinaire HAL, est destinée au dépôt et à la diffusion de documents scientifiques de niveau recherche, publiés ou non, émanant des établissements d'enseignement et de recherche français ou étrangers, des laboratoires publics ou privés. 


\title{
Robotic-flapper maneuvers and fruitfly turns
}

\author{
Studies of an aerial robot help explain rapid banked turns in the fruitfly \\ By Franck Ruffier
}

Winged insects have been a rich source of inspiration for designing flying robots, but robots can also be used to test hypotheses about the mechanisms underlying the control of insect flight (1). Winged insects perform continuously demanding tasks from takeoff to landing that include rapid turns as well as virtuosic chasing behaviors. During evasive maneuvers, the fruitfly executes rotations to achieve banked turns (2). On page 1089 of this issue, Karásek et al. (3) show that the accurate control of a new tailless, flapping-wing robot reveals how these insects perform rapid banked turns, even though the robot is much larger than a fruitfly. The similarities between the maneuver dynamics of the robot and that of fruitflies strongly support the hypotheses that rotation around the vertical axis (the "yaw" movement) is passively controlled throughout evasive maneuvers and that fruitflies actively control their heading only after executing these turns.

In addition to mating and food foraging, escaping from dangers such as predators is one of the main challenges of flying animals. Most escapes of flying animals involve rapid banked turns that can occur at different pitch-to-roll rate ratios [for the fruitfly, see (2)], corresponding to either roll-dominated or pitch-dominated maneuvers. Maneuvering an aerial robot that has kinematics similar to that of the fruitfly and that can freely execute any control-command sequences allows testing of hypotheses about the insect's flight. In particular, adding a yaw command did not make the robot of Karásek et al. turn more quickly. Thus, fruitflies may perform such evasive maneuvers as fast as possible without feedback information.

Karásek et al. also developed a functional, low-complexity model of aerodynamic yaw torque that explains the rapid banked turn of the robot. Specifically, two new terms were added: the so-called translation-induced coupled yaw torques. Each of the new yaw-torque terms depends on a product between a translational velocity and the torque command around the axis of this same translation. One-the roll command-is the product between the longitudinal velocity (the forward speed) and the angular acceleration around the longitudinal axes (roll rate). The other-the pitch command-is the product between the transverse velocity (the sideways speed) and the angular acceleration around the transverse axes (pitch rate). Such couplings were highly correlated with the biological flight data, so the fruitfly might use these torque couplings to passively induce yaw acceleration and execute rapid banked turns. 
Karásek et al. used their flapping-wing robot as a tool to better understand the sophisticated controlcommand system during escape behavior. Their meticulous design enables free flight with four control inputs, which is comparable to the helicopter-like simplified modeling of a winged insect (4). The lift force is produced by two bioinspired clap-and-fling mechanisms of the wings moving at $17 \mathrm{~Hz}$. The yaw torque is produced by changing the wing root angle asymmetrically, the pitch torque is produced by adjusting the dihedral angle, and the roll torque is produced by generating asymmetrical flapping lift. The asymmetrical frequency control of the clap-and-fling mechanisms relies on two independent motors. The independent mechanisms of the roll and pitch torque generation allow for different pitchto-roll ratios, and the robot can perform $360^{\circ}$ roll and pitch flips.

Such increased controllability let the authors test a full range of banked-turn maneuvers. In forward flight, $90^{\circ}$ banked turns are dominated by roll commands-low pitch-to-roll ratio. The roll commands rely on different techniques to generate the roll torque across the bioinspired aerial robot (see the figure). In forward flight, the pitch also controls the forward velocity, the yaw controls the heading, and the lift controls the altitude. A slightly smaller flapping-wing robot, the Nano Hummingbird, used a different asymmetrical lift mechanism to generate roll torque and also achieved an autonomous $360^{\circ}$ roll flip (5). This robot used an asymmetrical 30-Hz flapping-wing orientation, that combined both wing twist and angle-of attack modulation.

At the insect scale, a tiny $120-\mathrm{Hz}$ flapping-wing robot, the Robobee, used asymmetrical wing-stroke amplitude (6) to produce roll torque. At larger scales, roll control was achieved by disabling lift on the inside wing toward the desired turn. A 6-Hz flapping-wing, birdlike robot used spoilers (7), and a birdinspired glider used tip-feather ailerons (8). Recently, a roll-dominated banked-turn maneuver was reproduced with a small drone endowed with a distinctive morphing wing design composed of artificial feathers (9). The folding of these artificial feathers on the inside wing creates asymmetric surface morphing. Such an asymmetrical wing surface lets the drone turn rapidly without using conventional ailerons. Precisely gliding birds can achieve banked turns by flexing the wrist and elbow of their inside wing toward their desired turn, thus substantially reducing the inside wing surface (10).

Gliding is one solution to overcome the main challenge for aerial robots: their high energy consumption during powered flight. At high pitch, the double clap-and-fling configuration chosen by Karásek et al. also benefits from nonnegligible gliding effects that substantially increase its flight range. Indeed, the flight endurance increases with the robot mass in small drones (11), and the wingspan increases with the mass in flapping micro air vehicles (12). In bioinspired aerial robots, when the flapping frequency decreases, the wingspan, mass, flight endurance, and flight range generally 
increase (see the figure). Biomimetic aerial robotics that will integrate bioplausible perception and bioplausible flight mechanics could lead to further insights into animal behavior, such as puzzling aerial chasing behavior. Indeed, trials have been reported with bioprincipic robots typically equipped with propellers to test free-collision navigation hypotheses, as reviewed in $(13,14)$.

\section{REFERENCES AND NOTES}

1. N. Franceschini, Proc. IEEE 102, 751 (2014).

2. F. T. Muijres et al., Science344, 172 (2014).

3. M. Karásek, F. T. Muijres, C. De Wagter, B. D. W. Remes, G. C. H. E. de Croon, Science361, 1089 (2018).

4. G. Portelli, J. Serres, F. Ruffier, N. Franceschini, J. Physiol. Paris104, 27 (2010).

5. M. Keennon, K. Klingebiel, H. Won, in Proceedings of the $50^{\text {th }}$ American Institute of Aeronautics and Astronautics (AIAA) Aerospace Sciences Meeting Including the New Horizons Forum and Aerospace Exposition (AIAA, 2012), p. 588.

6. K. Y. Ma et al., Science 340, 603 (2013).

7. G. A. Folkertsma, W. Straatman, N. Nijenhuis, C. H. Venner, S. Stramigioli, IEEE Robot. Autom. Mag. 24, 22 (2017).

8. R. G. Hoey, Bioinspir. Biomim. 5, 045008 (2010).

9. M. Di Luca, S. Mintchev, G. Heitz, F. Noca, D. Floreano, Interface Focus7, 20160092 (2017).

10. D. R. Warrick, M. W. Bundle, K. P. Dial, Integr. Comp. Biol. 42, 141 (2002).

11. D. Floreano, R. J. Wood, Nature 521, 460 (2015).

12. H. Liu, S. Ravi, D. Kolomenskiy, H. Tanaka, Phil. Trans. R. Soc. B 371, 20150390 (2016).

13. M. V. Srinivasan, Physiol. Rev. 91, 413 (2011).

14. J. R. Serres, F. Ruffier, Arthropod Struct. Dev. 46, 703 (2017).

\section{ACKNOWLEDGMENTS}

I thank K. Trego-Ruffier for fruitful comments on the manuscript.

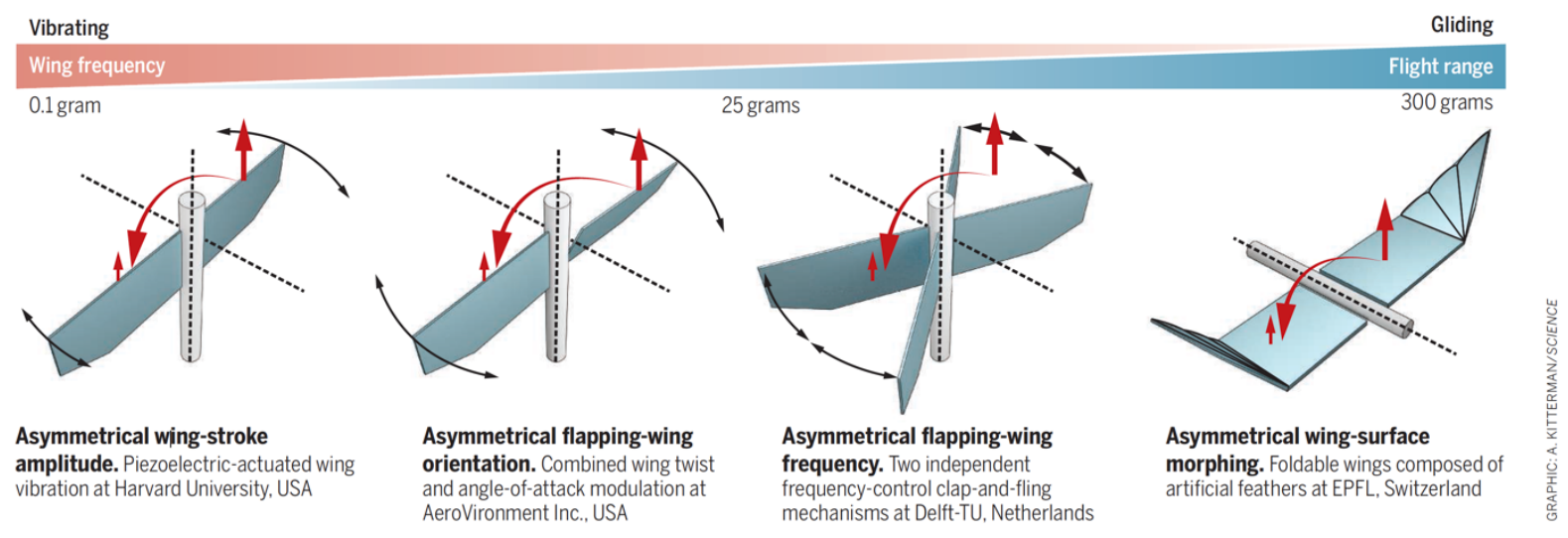

\section{Ready to roll}

Roll commands have been implemented with wing mechanisms for robots exhibiting various flight ranges. Various mechanisms exist, from powering the flight directly with the vibrating wings in lighter bioinspired robots (left) to relying on gliding in heavier bioinspired robots (right). 